\title{
Understanding Mobile Banking Success through User Segmentation
}

\author{
Luvai Motiwalla \\ U MASS Lowell \\ luvai_motiwalla@uml.edu
}

\author{
Mousa Albashrawi \\ KFUPM \\ bishrama@kfupm.edu.sa
}

\author{
Hasan B. Kartal \\ University of Illinois Springfield \\ hasan.kartal@uis.edu
}

\begin{abstract}
Mobile banking (MB) which involves the use of mobile devices to access bank accounts for conducting financial transactions has grown rapidly but unevenly with users. Banks realizes the strategic role of user's satisfaction and the importance of MB systems in their business models. Yet, the diversity of users and disparity of system usage behaviors make difficult to measure MB success. This study segments the MB users on system use behavior of 4,478 users with objective measures by analyzing the MB system log files on various system usage metrics. Then, a subjective measures study surveys the same users on the system success factors of the information systems (IS) success model by using 445 responses. Results indicate that the influence of success factors significantly varies among user segments for intention to use, which makes an important contribution to enhance interpretation of the IS success model.
\end{abstract}

\section{Introduction}

Bankers and researchers alike contend that user adoption of mobile applications is an effective way to improve the banking industry value and profitability [14]; [12]. Customer adoption and use of banking applications has grown rapidly but unevenly, with some consumers using mobile banking (MB) frequently and are even willing to pay for it, while others are just getting accustomed to this technology [7]. The one-size-fits-all approach to study the mobile application adoption and use is not appropriate for measuring today's system success [27] when financial firms are deploying new flexible strategies to personalize mobile systems to the micro needs and preferences of their users. Banks, similarly, need to determine their MB system success factors by tailoring functionality to the differing needs of their users. Head and Ziolkowski [13] first highlighted the issue of population segmentation in their study of mobile phone feature usage which found that increasing features creates negative attitudes and decreases system use due to "feature-fatigue" or functional overload. Instead, personalizing system features by the needs of user segment created a more positive attitude and satisfaction towards system use [13]. Similarly, Schacht et al. [27] found a better explanation of determinants for IS acceptance with segmented groups. This suggests that MB system success can be understood better with a homogeneous sample, instead of a heterogeneous (cross-sectional) sample.

Yet, the majority of information systems (IS) adoption and mobile usage studies use cross-sectional samples with an assumption that their models are valid and generalizable across consumer populations [13]. User homogeneity in samples provides a better understanding of the needs of different user groups and their usage of the system functions [13]. Recent studies have reported that lack of user segmentation has introduced statistical validity threats to empirical testing of behavioral study models such as TAM, UTAUT or IS success due to sample heterogeneity which biases the study results leading to invalid conclusions [3]; [27]. Prior research suggests user segmentation in a behavioral study is important because it enables researchers to better understand the factors influencing system use [3] and increase the mobile usage by adapting system features for individual customer needs [13].Customers segmented on demographic variable may not be homogeneous on their mobile functional use perceptions [13]; instead, using other variables like system use can help reduce the unobserved heterogeneity. When samples are segmented by demographic variables like age or gender or education [27], or geographic region [21], they are used either as control variables or Finite Mixture Partial Least Squares (FIMIX-PLS) approach [3]. We have not found a study that has stratified or segmented the users based on their usage behavior from the system logs to measure system success.

In this study, we have segmented the MB users on their system use behavior with an objective measures study. We have analyzed the MB system log files which capture behavior on a variety system usage metrics. Objective measure studies are not common in system usage [9]. Extant mobile usage research has relied mainly on subjective measures focusing on the 
antecedents of behavioral intention to use during initial adoption or continued use intention [10]. System usage has been studied extensively in IS literature [5], but most studies prefer subjective over objective measures [34]. While a subjective measure like the intention to use is important, it is not as powerful as an objective measure, like the actual use of the system [9]. Actual use measures include frequency of use [19], and feature utility [13] are best observed through the objective measures. Actual use captures user behavior through the system log files [34] or through newer psychophysiological tools like eye-tracking [9]. Subjective measure studies tend to have self-selection and self-reporting biases which limit their validity [18]. Segmenting user sample based on their system use, a dependent variable of most IS adoption and usage studies, with data analytic techniques can uncover limitations of unobserved heterogeneity sample biases that may exist in prior MB adoption studies. The IS success model has not been tested with segmented user groups. Measuring IS success, in a customer focused era with more customized information systems, can be complex because adoption rates may vary among user groups; one group may believe the system is successful, while another group may reject it completely. With a more diverse and personalized usage of MB systems today, we feel it is important to understand system success with homogeneous user groups that have similar use behaviors, instead of one heterogeneous sample.

The research questions we address through this study are: 1) Is the influence of the success/quality factors on satisfaction and intention to use different in the various segments than in the global model? 2) Does one success/quality factor have a higher influence in one segment over the other segments? 3) Is the overall explanatory power of the IS success model higher in full sample or in the segmented samples?

We tested our IS success model with a combined objective and subjective measures study. In the objective study, MB system log data file with usage behavior of 4,478 customers from previous eight months was analyzed with cluster analysis to segment them into three user groups: light, moderate and heavy users. In the subjective study, the same users were surveyed, by the bank, using constructs from IS success model adapted from prior studies in mobile context. The influence of independent variables from IS success model such as system, information and service quality was assessed on the dependent variables such as satisfaction and intention to use. This latter variable helps the understanding of the long-term continued use of mobile banking and customer retention within the homogeneous groups. Results from analysis of a field survey of 445 users indicate that the influence of success/quality factors was different for the three user groups intention to use. For example, service quality did not influence heavy users' satisfaction, but it did influence light and moderate users, and the intention to use was very different for light users when compared to moderate and heavy users.

Our study provides three valuable contributions. First, we have utilized the system use variable of IS success model to analyze the system log data files with objective measures, to segment the users into homogeneous groups. This we believe provides an alternative approach to reduce statistical validity threats from empirical behavioral studies due to sample heterogeneity. Second, we have used both system use and intention to use in our model. System use was analyzed from the log files, and then the same users were probed on their satisfaction and intention to use. This complementary behavioral analytics approach of system use behavior from log files and intention to use from the survey improves understanding of system success. We have not found a study that has analyzed system use and intention to use with the same users from two alternate data sources. Finally, comparing the various IS success factors influence on user satisfaction and intention to use amongst the different user segments allows us to determine the success of MB system in homogenized groups increasing the explanatory power of the model.

\section{Related Work}

System use or usage, a key measure of the information systems success, represents the extent to which the system capabilities are utilized by customers. Prior research has measured actual system use but mostly with subjective measures which estimate system use through self-reported surveys. For example, Straub et al. [32] measured the usage of a voice mail system objectively through computerrecorded data and subjectively through self-reported survey data using the TAM model to address the conceptual and methodological issues associated with system usage measurement construct. Joo et al. [15] used the access frequency to objectively measure the usage of a mobile e-learning system with students from South-Korean online university. These studies report that objective measures capture usage more accurately than subjective measures yet, few studies have employed objective measures for system usage [34] due to the difficulties associated with the access and collection of system use data.

MB research has not focused much on actual system use [39], even though it is a better predictor of information system success, satisfaction and intention to use [8]. Research on online banking has been 
fragmented [23] and has focused mainly on preadoption using either the technology acceptance model (TAM) or the unified theory of acceptance and usage of technology (UTAUT) model, derived from IT adoption theories [10]. More attention has been paid recently to customer behaviors in the post-adoption stage with the IS success model. Kim and Son [16] provide the benefits of studying system use for understanding the full potential of IT investments and success factors of online e-commerce firms. Similarly, understanding of MB actual system use behavior can help the banking industry.

The IS success model has validity in measuring the success of mobile systems [11]. Prior studies have generally found that systems quality which measures technical success, information quality which measures semantic success, and service quality which measures customer service affects user satisfaction positively and increases system use and net benefits. For example, IS success model has been used for studying the impact of trust and satisfaction in mobile banking [17] and understanding user satisfaction, trust, flow and continued use intention with mobile payment systems [39]. This latter study, which did not measure net benefits, was used as a basis for our study. Another reason for not using net benefits at this stage of adoption was due to the relative newness of $\mathrm{MB}$ system adoption. Users may not be able to accurately assess and quantify the net benefits at this early stage of adoption.

Instead, our interest was more in understanding user satisfaction and intention to use the MB system. Intention to use implicitly reflects customer loyalty and retention [10], and therefore a more useful measure for the banks. Intention to use was included as a dependent variable in the updated IS success model [8] to resolve the process versus causal concerns raised by [29] and could be used in contexts where it is important to understand user attitude [22] towards the continued system use [10].

In our study, we are also interested in understanding the attitude of the MB users towards future intention to use which helps us understand their loyalty towards the MB system. Also, the system use data was used as an objective measure to segment the users into groups and could not be used again for the same sample. This method supports the suggestion from [8, p.23] that "use must precede user satisfaction." The inclusion of satisfaction and intention to use as dependent variables make the IS success model appropriate for our study.

Finally, prior mobile adoption studies have not used IS success model with a segmented user population by their system use volume and feature usage to understand the determinants of system success. They have not used the dependent variable (system use) from the IS success model for segmenting the user sample. There is no analysis available on how the IS success factors perform in homogeneous user groups segmented by their usage behavior. Segmentation of users allows us to compare the MB systems' success factors, satisfaction, and intention to use among the user groups. Segmentation has been used in marketing research to determine adopter categories [20] in the pre-adoption or intention to use of technology [31]. But, it has not been used in post-adoption for a categorization of users. When used, it is mostly on demographic variables never by usage behavior [13]. In this study, we are segmenting user sample into a priori groups based on their MB system use with cluster analysis on the log data file followed by a field study with the same users with the IS success model.

In sum, our behavioral-analytics approach provides a comprehensive and insightful analysis of MB usage and success which, to the best of our knowledge, has not been used by any prior system usage studies. First, we have analyzed users' behaviors in MB system through objective measures study with eight-month data from MB system log files which capture a wide variety of user activities from mobile devices. These same users were then probed through the subjective measures from a field survey using IS success factors for MB use.

\section{Hypotheses Development}

The IS success model was adapted for understanding MB success with both objective and subjective measures study discussed in this section. The system use variable was used to segment the users into groups based on their usage behavior followed by a field survey with the same users whose system use was analyzed through the log data file. The survey responses were matched to each user in the log file. This mix-method approach helps mitigate weaknesses of one method with the strengths of the other [9] and allows us to reveal the differing influences of the three system success/quality factors with homogeneous user segments.

\subsection{Subjective measures study}

The IS success model is capable of determining user satisfaction and intention to use a new system based on three quality factors [8]. The data from this study was analyzed both as a single group and segmented user groups. Discussed below are the three quality factors of IS success where were our independent variables in our field study, while user satisfaction and intention to use are our dependent variables. 
3.1.1. System quality (MQ) describes the degree to which the mobile system is visually appealing and easy to use and navigate [39]. System quality reflects the easy access of different and trustworthy services. For example, MB system that enables reliable and flexible banking services can enhance customers' satisfaction level. On the other hand, poor interface and difficulty to navigate lower the satisfaction level among MB users. A meta-analysis study [24] finds strong influence for system quality on user satisfaction and intention to use.

3.1.2. Information quality (IQ) describes the degree to which the mobile system provides relevant, sufficient, and accurate information [39]. Since customers may struggle to find their banking information because of the small screen size, how information is organized and presented in MB can influence their level of satisfaction. A meta-analysis study [24] finds strong influence for information quality on user satisfaction and intention to use.

3.1.3. Service quality (SQ) describes the degree to which the mobile system provides timely, responsive, and personalized services to users [39]. Service quality emerges in the dimensions of assurance, reliability, empathy, and responsiveness, infrastructure and/or appearance over the past 20 years [37]. Empirical IS research confirms that high service quality of the system affects user satisfaction [6]; [37]. This relationship is also validated in mobile technology context [39].

3.1.4. Satisfaction (ST) refers to the emotional reaction that individuals show when interacting with MB services [6] whereas intention to use in IS research refers to the "degree to which a person has formulated conscious plans to perform or not perform some specified future behavior" [33, p. 484]. Rationally, users who feel they are being well-served will show a greater level of satisfaction towards MB, which in turn leads to increase their continuous engagement to the system. DeLone \& McLean [8] suggest that due to the complexity of measuring system use, intention to use can be worthwhile involuntary use contexts as well as can be predicted by user satisfaction. A meta-analysis study [24] also finds strong influence for user satisfaction on intention to use.

3.1.5. Intention to use (IU) refers to the attitude of the users on future use the system. DeLone \& McLean [8] have not operationalized intention to use construct. Predicting success has been a key objective of IS adoption research with TAM and UTAUT models doing a better job in measuring intention to use [22]. Mardiana et al. [22] justified the inclusion of intention to use in the IS success model to understand the user attitude for using the system in future which was not captured by the use which is post-acceptance behavior.
Both Gao and Bai [10] and Zhou [39] have used the intention to use construct from TAM and UTAUT model in their study for use with IS success model, which we have done in our study.

Based on the above review, we hypothesize that:

H1: System quality positively influences user satisfaction.

H2: Information quality positively influences user satisfaction.

H3: Service quality positively influences user satisfaction.

H4: User satisfaction positively influences intention to use.

\subsection{Objective measures study}

Objective measurement of system usage is considered as an important technique to capture user behavior with systems but has been difficult method due to data availability and privacy issues [34]. Our goal here was to test the validity of IS success model with homogenous groups segmented by their system use behavior. Different user segments may value different MB success factors [13]; [35]. Users that use the system regularly, namely heavy users, may have different system success factors than the light users who use system infrequently. System, information, service quality, use, user satisfaction, individual benefits and organization impacts are still relevant in today's customer-focused system era. But, voluntary and hedonic use has increased the complexity of measuring system success and changed the metrics relevant to these factors. Further, the personalization of systems must recognize the varying perceptions of different user groups and individuals [34]. One group may see a system as successful while another group may see it as a failure.

System use in the voluntary use context has been measured by frequency of use, time of use, the number of logins, or as a binary variable of use/non-use [8]. Burton-Jones and Straub [5] have extended the measurement scale to categories system use from lean to rich. Lean measures determine usage based on a simple measure like use/non-use, the frequency of use of a system features, and duration of use. While rich measures determine usage based on the extent to which a user understands and employs the system features to accomplish a task. They reflect on the users' cognitive absorption of system features and use for complex tasks that involve multiple interactions between system and users. We have adapted some of these system use measures to categorize the MB use behaviors into the light users, moderate users and heavy users' segments. The log data file we used for our analysis captures a multitude of user activity with 
MB system. This includes the amount of money that was transferred, deposited and paid to vendors by the users as well as the frequency of logins, the number of time they check their account balances and the number of deposits. Collectively, this information provided us with diverse use behaviors to cluster our user sample into heavy, moderate and light user groups. We have therefore segmented our users into a priori groups by analyzing the system log file with cluster analysis.

Cluster analysis has been a popular method of segmenting customers in marketing research [35] and has been used in IS research successfully for discovering user behaviors in online shopping based on website visits, clicks or orders [30] as well as studying switching behaviors on website portals [18] and more recently understanding customer migration behavior in mobile service usage and revenue patterns [4]. Clustering users on their mobile usage patterns, before determining the antecedents or consequents affecting system usage, provide a better understanding of system success factors than cross-sectional studies which assume models can be generalized to any user population [36]. A "one-size-fits-all system usage model can be misleading as different consumer segments (segmented by perceived feature utilities rather than demographics) may value different constructs or experience different causal relationships in the model" [13]. User homogeneity provides a better understanding of the needs of different user groups and their usage of the system functions [34]. For example, heavy users will have different expectations and perceptions of the same system as compared to the light users. Heavy users use the system frequently and access basic to advanced features of the system, and have a different level of confidence and system use experience [3]. This often leads to a different level of satisfaction and use, as compared to the light users. Similarly, it is possible that light users are using limited MB features, but still have the same level of satisfaction as a heavy user.

Our research addresses the validity issue with more homogeneous user segments. Incorporating segmentation methods from the marketing domain [35] provides a more comprehensive and richer understanding of mobile user preferences and motivations for use [13]. Similarly, Schacht et al. [27] observe that IS adoption studies have used segmentation from marketing research to group either by users' system experience, age or by their adoption stage [25]. Segmenting a large diversified user group is important when system usage is voluntary, as in mobile banking. Unlike employees, consumers are not mandated to use these systems [8]. Determination of system success is more difficult when users' motivations and reasons for use are diverse. For example, heavy user segment may be highly satisfied and use the MB system for its information and service qualities, while moderate user segment may be somewhat satisfied and use the MB system for its system quality. On the other hand, light users may not be satisfied with the system due to its system quality. Our study will attempt to reveal the differing influences of the IS success factors on the different segments and identify whether significant differences exist amongst the segments.

H5: The influence of success/quality factors on user satisfaction and intention to use are higher in the segments than in the full sample

H6: The influence of success/quality factors on user satisfaction and intention to use varies amongst the segments

\section{Research Model}

Analyzing survey data by the user segments, as shown in Figure 1, will improve the validity of our results and allow comparisons of system success amongst the light, moderate and heavy user groups. Prior research has not used this approach of segmenting users in the sample with the data analytics approach on the system usage construct [5] or with the IS success model [8]. We believe our approach will provide a better understanding of the MB system usage.

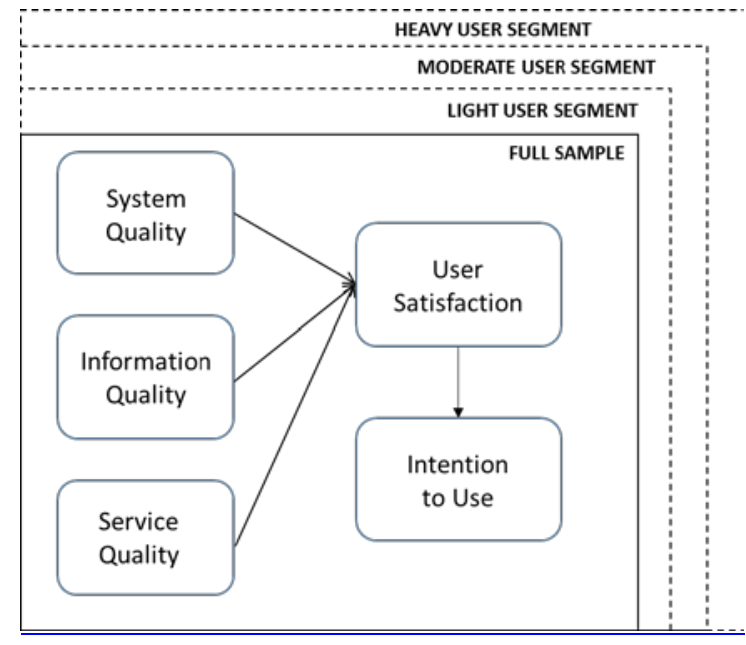

Figure 1. Research Model

The success of MB system is determined by comparing the quality factors between each user segments from our cluster analysis. Assuming our clustering reveals three categories, as shown in Figure 1 , our hypothesis will recognize different perceptions of system success amongst the segments 


\section{Research Method and Data Analysis}

Our objective measures study analyzed the MB system log data file with cluster analysis to segment users into homogeneous groups, and our subjective measures study analyzed the field survey data, using constructs from the IS success model [8], with the same users. The log data file was given to us from the bank's mobile billing analytics and reporting file. This file contained detail MB use data on 51 attributes such as customer identifier number, name, date of first registration, number of activities on various banking transactions like balance checks, transfers, bill payment, deposits to the total amounts of deposits, payments, transfers, and bill payments all of which captures the MB system usage. Survey data was collected from local mid-sized US bank customers in the northeastern region. The bank sent an invitation email to their customers with a survey link and donated $\$ 1000$ to a charity organization as an incentive to participate in the study. Participation was voluntary, and customers could opt out any time during the survey. The survey was open for about 20 days with a follow-up reminder sent every 10 days to help in collecting a sufficient sample. A key challenge was linking and integrating survey and log file data while protecting user privacy. The bank matched users from log data file with the survey responses and sent us the combined data file after anonymizing the user identity. Below is a brief review of our two research methods.

Cluster analysis is an unsupervised machine learning method for grouping objects that have similar characteristics based on their distance between objects from a mean vector. It groups a data matrix composed of $n$ observations (rows) and $p$ variables (columns) into homogeneous segments without any data transformation as in principal component analysis [11]. A variety of clustering techniques are available depending on the goals of clustering [2]. Broadly, they are categorized into hierarchical and partitioning algorithms. The hierarchical technique either uses agglomerative or divisive algorithms where objects are divided into parent-child relationships using trees. While flexible and easy to handle, they are vague on the termination criteria and work on the presumption that clusters consist of similar objects. Partitioning algorithms use iterative learning heuristics like probabilistic, k-medoid and k-mean methods to fit objects into homogeneous clusters by revisiting clusters after every iteration formation, gradually improving the clusters.

An online survey was conducted by the bank with all users found in their system log file. The survey used constructs adapted from prior mobile-context studies [39]; [10] that have used the IS success model and focused on the system, information, and service qualities, as well as satisfaction and intention to use. The latter variable was adapted from Venkatesh et al. [33]. All constructs items were adapted from previous research to ensure face validity. The items are measured via a 7-point, Likert-scale with 7 "Strongly agree" and 1 "Strongly disagree." We analyzed the survey data by user segments created from cluster analysis. This approach allows us to determine system usage success by segment and determine whether significant differences exist or not between the groups. It also allows us to minimize the threats of statistical validity from sample heterogeneity [3] providing a better understanding of MB usage.

\section{Objective Measures Analysis}

With the collaboration of the bank, a log file gathered from the online service users of the bank. The file consists of 5,116 total number of user's data who were registered customers anytime during an eightmonth period, which resulted in 58,356 unique monthly observations. We aggregated all observations for each user using a unique customer identifier. Out of 51 attributes of the log file, we extracted seven attributes which help us understand the usage behaviors of the MB users for an eight-month of observation period, and used the registrant identifier as eight attributes. The remaining 43 attributes are identifier variables, flags and other system log data that does not focus on usage activities were discarded.

Some users are early registrants who have the full eight months of observations, while the other users are late registrants who have limited observations varying from one month to seven months. To improve the reliability of the user activities, we have only analyzed the data for 4,478 registrants' data who possess at least six-month of account activity. To have a fair representation of varying (six, seven and eight months) lengths of the accounts, we aggregated each user's monthly account activities and scaled them into a monthly base. We also removed 740 registered MB users who had no recorded activity during the examined eight months. The final dataset was reduced to 3,737 registrants each corresponds to a unique registrant identifier and the monthly averaged observations of seven measures of user behaviors. Because the log data were collected in continuous values, for consistency through the analysis, values of experience and actual use from the log data were first rescaled with min-max normalization, then transformed into 7-point Likert-scale using the techniques suggested by Aiken [1] for data normalization and cluster analysis.

In an average month, many users have less than one activity for most attributes except other activities. 
The average for the transfer amounts is less than $\$ 500$, the bill payments is less than $\$ 90$, and the submitted deposits is just above $\$ 130$. The standard deviations of each attribute are high as many as three to five times the mean values, indicating that the users are diverse in their MB usage behaviors.

For the cluster analysis, we matched the log data and survey data collected from the users. As a result of this matching processes aggregated data contained 472 complete sample. The description of survey data and the details of the matching process is explained in the next section. The ultimate data size was reduced to 445 participants because we removed $2 \%$ from the highest and lowest values in our data to overcome the skewness problem in our sample and produce effective cluster analysis. We followed the data preprocessing method used successfully by Bose and Chen [4] for customer segmentation. We considered two types of attributes during clustering. First, usage frequency indicates the extent of usage, e.g. the number of times a user requests money transfer, bill payments, mobile deposits or other transactions; second, the dollar amount of usage indicates the amount of money processed in a transaction like money transfers, bill payments, mobile deposits reflect rich usage of the MB system. Using the average usage frequency and dollar amount of usage, users are respectively clustered into 2, 3 and 4 clusters. 2-cluster, 3-cluster, and 4-cluster. Using both "elbow criterion" and a visual inspection of the dendrogram generated by Ward's hierarchical clustering algorithm indicated the validity of 3-cluster solution in our dataset.

To ensure a more balanced and reliable clustering solution, we used two clustering techniques; k-means and PAM (k-medoids). k-Means partitions observations into $k$ clusters based on the minimized Euclidean distance; PAM does the same but based on Manhattan distance. PAM is more robust than kmeans when working with extreme values because of its insensitivity to outliers, hence, we employed it alongside with k-means to decide on which fits our data best. Table 1 shows the 3-cluster solution for both k-means and PAM with usage classification:

Table 1. The 3-Cluster Solution

\begin{tabular}{|c|c|c|c|}
\hline Method & $\mathbf{1}^{\text {st }}$ Cluster & $\mathbf{2}^{\text {nd }}$ Cluster & $\mathbf{3}^{\text {rd }}$ Cluster \\
\hline \hline k-means & 305 & 117 & 23 \\
\hline PAM & 209 & 141 & 95 \\
\hline
\end{tabular}

PAM generated a more balanced and stable solution than k-means (Table 1) and accordingly was chosen for our study. PAM's 3-cluster solution was validated using Silhouette method [26] reflecting a better placement of each observation in each cluster. Silhouette improves the results of cluster analysis, and its average width can be used to provide an assessment of cluster validity. The higher Silhouette coefficient, the better cluster validity. PAM's 3-cluster solution had a positive coefficient, which indicates our observations were clustered properly. The $3^{\text {rd }}$ cluster representing heavy users has much higher usage on all attributes compared to the other two clusters.

\section{Subjective Measures Analysis}

The bank log file contained many user identifiers that could indetify the actual users. Therefore, the survey was conducted by the bank matched to the users from the log data file, de-identified, and given to us through a secured file access so as not to violate the requirements of our IRB. De-anonymized survey responses were matched with users in the log data with a de-identified unique consumer registrant number assigned by the bank. This process guaranteed matching between the log and survey data without compromising the individual privacy.

\subsection{Participants demographics}

Figure 2 below provides the demographic profiles of three user groups, light, moderate, and heavy by their gender, age, and education, which when combined with MB success factors and usage data from log files provide a better understanding of system success. In the light usage cluster, we note that majority of light users were males with ages greater than 46, education levels of college degree or higher, as well as with fulltime jobs. In the moderate and heavy usage clusters, the demographics for the majority groups were quite the same except for gender; the most of the moderate and heavy users were females.

\begin{tabular}{|c|c|c|c|c|c|c|c|}
\hline \multirow{2}{*}{\multicolumn{2}{|c|}{ Demographics }} & \multicolumn{6}{|c|}{ Segments } \\
\hline & & \multicolumn{2}{|l|}{ Light } & \multicolumn{2}{|c|}{ Moderate } & \multicolumn{2}{|c|}{ Heavy } \\
\hline \multirow{2}{*}{ Gender } & Male & 109 & & 62 & $4 \%$ & 35 & $3 \%$ \\
\hline & Female & 100 & $48 \%$ & 79 & $56 \%$ & 60 & 635 \\
\hline \multirow{6}{*}{ Age } & $15-25$ & 19 & $9 \%$ & 19 & $13 \%$ & 9 & $9 s_{4}$ \\
\hline & $26-35$ & 22 & 115 & 25 & $18 \%$ & 10 & $11{ }^{\circ}$ \\
\hline & $36-45$ & 34 & $16 \%$ & 22 & $16 \%$ & 19 & 200 \\
\hline & $46-55$ & 58 & $28 \%$ & 32 & $23 \%$ & 21 & $2 \%$ \\
\hline & $56-60$ & 27 & $13 \%$ & 17 & $12 \%$ & 12 & $13 \mathrm{~s}^{2}$ \\
\hline & $>60$ & 49 & $23 \%$ & 26 & 180 & 24 & 284 \\
\hline \multirow{5}{*}{ Education } & High school & 22 & $11 \%$ & 19 & $136_{0}$ & 13 & 145 \\
\hline & Some college & 58 & $28 \%$ & 36 & $260_{0}$ & 31 & 33 \\
\hline & College degree & 74 & $35 \%$ & 42 & $30 \%$ & 23 & 24 \\
\hline & Graduate degree & 54 & $26 \%$ & 42 & 300 & 27 & 28 \\
\hline & \begin{tabular}{|l|l} 
Other \\
\end{tabular} & 1 & $0 \%$ & 2 & 10 & 1 & 16 \\
\hline \multirow{5}{*}{ Profile } & Full-time & 141 & $6 \%$ & 92 & 6550 & 61 & $6+4$ \\
\hline & Part-time & 25 & $12 \%$ & 20 & $1 w_{0}$ & 11 & $12 \%$ \\
\hline & Unemployed & 3 & $1 \%$ & 9 & 60 & 4 & 4 \\
\hline & Retired & 35 & $1 \%$ & 16 & 116 & 17 & 18. \\
\hline & Student & 5 & $2 \%$ & 4 & 340 & 2 & $2 \mathrm{st}$ \\
\hline
\end{tabular}

Figure 2. Demographics Analysis of the Three Clusters 


\subsection{IS Success model validity and results}

Confirmatory analysis was employed to evaluate the psychometric properties of the used measures. As per our data analysis, all loadings for constructs' items were greater than accepted level of 0.5. Similarly, discriminant and convergent validity, Cronbach's reliability, composite reliability, and variance inflation factor (VIF) for both full and segmented samples were all established as their values were above the literature recommended thresholds.

The structural model was tested with the full and segmented samples via structural equation modeling (SEM) technique. SEM results indicate that all quality factors (system, service, and information) were significant determinants of user satisfaction in the full sample and the three clustered samples except for heavy usage cluster. In the heavy usage cluster, system quality and information quality were important indicators, but service quality is not (Table 2).

Table 2: Structural Model Results

\begin{tabular}{l|c|c|c|c|c|}
\hline Hypothesis & Full & Light & Moderate & Heavy \\
\hline \hline H1:MQ $>$ ST & $0.437^{* *}$ & $0.449^{* *}$ & $0.412^{* *}$ & $0.410^{* *}$ \\
\hline H2: IQ $>$ ST & $0.307^{* *}$ & $0.302^{* *}$ & $0.220^{*}$ & $0.430^{* *}$ \\
\hline H3: SQ $>$ ST & $0.175^{* *}$ & $0.201^{*}$ & $0.230^{*}$ & 0.048 \\
\hline H4: ST $>$ IU & $0.373^{* *}$ & $0.521^{* *}$ & 0.216 & 0.350 \\
\hline
\end{tabular}

A multivariate analysis of variance (MANOVA) test was used to examine whether the difference between group means of the dependent variables exist. MANOVA test statistics, including Pillai's Trace, Wilks' Lambda, Hotelling's Trace, and Roy's Largest Root, were all significant ( $\mathrm{p}$-value $<0.01$ ), confirming that there is a significant difference between group means of intention to use across the three clustered models (Table 3).

Table 3. Summary of Results of Multivariate Analysis of Variance

\begin{tabular}{|l|c|c|c|c|c|}
\hline $\begin{array}{c}\text { Dependent } \\
\text { Variable }\end{array}$ & $\begin{array}{c}\text { Sum of } \\
\text { squares }\end{array}$ & Df & $\begin{array}{c}\text { Mean } \\
\text { square }\end{array}$ & F & Sig. \\
\hline Satisfaction & 5.242 & 2 & 2.621 & 1.997 & 0.137 \\
\hline Intention to Use & 15.916 & 2 & 7.958 & 7.771 & $0.000^{* *}$ \\
\hline
\end{tabular}

For deeper analysis, a post hoc test (Table 4) was performed to distinguish which cluster differs significantly from other clusters; this test revealed that MB light users differ significantly from moderate and heavy users, but no significant difference exists between the means of moderate and heavy users. Overall, this suggests that light users have very different success measures than moderate or heavy users and the IS success measures in our study have differing influences on user satisfaction and intention to use for the full user group than for the three homogeneous segments.

Table 4. Post Hoc Test

\begin{tabular}{|c|c|c|c|c|}
\hline $\begin{array}{c}\text { Dependent } \\
\text { Variable }\end{array}$ & $\begin{array}{l}\text { Cluster } \\
\text { (I) }\end{array}$ & $\begin{array}{c}\text { Cluster } \\
\text { (J) }\end{array}$ & $\begin{array}{c}\text { Mean } \\
\text { difference } \\
\text { (I-J) }\end{array}$ & Sig. \\
\hline Intention to Use & Moderate & Light & $0.291 *$ & 0.024 \\
\hline - & Heavy & Light & $0.460^{* *}$ & 0.001 \\
\hline - & - & Moderate & 0.171 & 0.417 \\
\hline
\end{tabular}

\section{Conclusion}

This research has presented an innovative mix method study using objective and subjective measures to increase the explanatory power of the IS success model. The combination of objective and subjective measures overcomes the limitations of prior IS usage studies that focus only on subjective measures [9], and the segmentation of our sample eliminates some of the bias from heterogeneous samples [3], both of which improve the validity of our study. The use of data analytics approach to study MB system use by segmenting the users into three groups which were surveyed on the IS success model constructs makes both theoretical and practical contributions.

Cluster analysis grouped our users into three homogenous segments: light, moderate and heavy users. These segments were formed by using objective measures from the system log files. We have used a well-established data analytics approach on a large user sample and IS theory on the system usage considering multiple factors and demographics influencing MB usage. A field study with user segments using factors from the IS success model provides a deeper understanding of success with homogeneous groups. Our preliminary analysis of data with segmented groups looks promising. One limitation was our cluster sizes were uneven which may have influenced some of the results, but the sample sizes were adequate for the analysis. Another limitation is that our findings cannot be generalized to all banks because all users were selected from one mid-sized urban bank.

Theoretical contributions from this study are the application of IS success model for MB usage and segmenting users into groups based on their $\mathrm{MB}$ system usage behavior with a data analytics approach. System use, which is a dependent variable of the IS success model, was used to segment users with cluster analysis, a data mining technique. This is the first study to use a dependent variable from the IS success model for segmenting the user sample. Our behavioral 
analytics approach can be used by other researchers for a better understanding of IS usage studies to reduce bias in parameter estimation and inferential errors through segmentation. Also, it will enable researchers to better understand the factors influencing usage [3], improve MB usage by considering individual needs [27] and increase the overall system use through personalization. Finally, it allowed us to test the IS success model factors with a more homogeneous user group, thereby reducing the chances of statistical validity errors often caused by observed or unobserved heterogeneity in the sample and a likely cause of validity problems due to Type I or Type II errors that affect IS adoption or usage study results [3].

This latter theoretical contribution also has practical contributions. Analyzing MB success by segments can help banks make better decisions on customizing system features when combined with the demographic data about each user group, like their gender, age, education and income information from the subjective study. Banks can use our approach for supporting more specific system features that are tailored for smaller user groups, thereby increasing customer loyalty, and bank revenue. This will also increase MB system usage and enhance the chances for system success. From a practical standpoint, the use of cluster analysis to segment the users into homogenous groups proved beneficial for the banks. It allows banks to understand which quality factors of the IS success model were more influential with the heavy, moderate and light user groups. Cluster analysis has been used to identify consumer segments on the basis of product usage variables in marketing research [28] and justifies its use for measuring system success. A priori clustering based on their usage behavior allows a more granular understanding of customers' behaviors without violating their individual privacy. Second, it allows the banks to introduce personalized $\mathrm{MB}$ functions features, services, and incentives that are customized to the needs of these segments improving system success in a highly competitive financial technology market.

\section{9, Acknowledgement}

We would like to thank Enterprise Bank Lowell for their support and data for this project.

\section{References}

[1] Aiken, L. R., "Formulas for Equating Ratings on Different Scales,” Educational and Psychological Measurement, 1987, 47, (1), pp. 51-54.

[2] Berkhin, P., "A Survey of Clustering Data Mining Techniques,” In Grouping multidimensional data, Springer Berlin Heidelberg, 2006, pp. 25-71.
[3] Becker, J.-M., Rai, A., Ringle, C. M., and Völckner, F., "Discovering the Unobserved Heterogeneity in Structural Equation Models to Avert Validity Threats," MIS Quarterly, 2013, (37), pp. 665-A21.

[4] Bose, I. and Chen, X., 2015. Detecting the migration of mobile service customers using fuzzy clustering. Information \& Management, 52(2), pp.227238.

[5] Burton-Jones, A., and Straub, D., "Reconceptualizing System Usage," Information Systems Research, 2006, 17, (3), pp. 228-246.

[6] Cenfetelli, R. T., Benbasat, I., and Al-Natour, S., "Addressing the What and How of Online Services: Positioning Supporting-Services Functionality and Service Quality for Business-to-Consumer Success,” Information Systems Research, 2008, 19, (2), pp. 161181.

[7] Crowe, M., Tavilla, E., and McGuire, B., "Mobile Banking and Mobile Payment Practices of US Financial Institutions: Results from 2014 Survey of FIs in Five Federal Reserve Districts,” 2015, pp. 1-66.

[8] DeLone, W. H., and McLean, E. R., "The DeLone and McLean Model of Information Systems Success: A Ten-Year Update,” Journal of Management Information Systems, 2003, 19, (4), pp.9-30.

[9] Eckhardt, A., Maier, C., Hsieh, J.J., Chuk, T., Chan, A., Hsiao, J. and Buettner, R., "Objective Measures of IS Usage Behavior under Conditions of Experience and Pressure using Eye Fixation Data," Thirty-Fourth International Conference on Information SystemsMilan, 2013.

[10] Gao, L. and Bai, X. Asia Pacific Journal of Marketing and Logistics, 2014, 26, (2), pp. 168-189.

[11] Giudici, P. and Figini, S., 2009. Market basket analysis. Applied Data Mining for Business and Industry, Second Edition, pp.175-191.

[12] Gu, J. C., Lee, S. C., and Suh, Y. H., "Determinants of Behavioral Intention to Mobile Banking," Expert Systems with Applications, 2009, 36, (9), pp. 1160511616.

[13] Head, M., and Ziolkowski, N., "Understanding Student Attitudes of Mobile Phone Features: Rethinking Adoption through Conjoint, Cluster and SEM Analyses," Computers in Human Behavior, 2012, 28, (6), pp. 2331-2339.

[14] Huang, D., “Mobile’s Rise Poses a Riddle for Banks,” Wall Street Journal, 2014, Dec. 18, www.wsj.com/articles/mobiles-rise-poses-a-riddle-forbanks-1418945162.

[15] Joo, Y. J., Lim, K. Y., and Lim, E., “Investigating the Structural Relationship among Perceived Innovation Attributes, Intention to Use and Actual Use of Mobile Learning in an Online University in South Korea," Australasian Journal of Educational Technology, 2014, 30, (4), pp. 427-439.

[16] Kim, S. S.. and Son, J.Y., 2009. "Out of Dedication or Constraint? A Dual Model of Post-Adoption 
Phenomena and its Empirical Test in the Context of Online Services,” MIS Quarterly, pp.49-70.

[17] Lee, K. C., and Chung, N., "Understanding Factors Affecting Trust in and Satisfaction with Mobile Banking in Korea: A Modified DeLone and McLean's Model Perspective,” Interacting with Computers, 2009, 21, (5-6), pp. 385-392.

[18] Lee, Y., Kozar, K. A. and Larsen, K. R., "The Technology Acceptance Model: Past, Present, and Future," Communications of the Association for Information Systems, 2003, 12, (1), pp. 752-780.

[19] Lu, H.P. and Gustafson, D.H., 1994. An empirical study of perceived usefulness and perceived ease of use on computerized support system use over time. International journal of information management, 14(5), pp. 317-329.

[20] Mahajan, V., Muller, E. and Srivastava, R.K., 1990. Determination of adopter categories by using innovation diffusion models. Journal of Marketing Research, pp.37-50.

[21] Mallat, N., Rossi, M., Tuunainen, V. K., and Öörni, A., "The Impact of Use Situation and Mobility on the Acceptance of Mobile Ticketing Services,” In System Sciences, 2006. HICSS'06. Proceedings of the 39th Annual Hawaii International Conference, 2006, 2, pp. 42b-42b. IEEE.

[22] Mardiana, S., Tjakraatmadja, J. H., and Aprianingsih, A., "DeLone-McLean Information System Success Model Revisited: The Separation of Intention to UseUse and the Integration of Technology Acceptance Models," International Journal of Economics and Financial Issues, 2015, (5), pp. 172-182.

[23] Montazemi, A.R. and Qahri-Saremi, H., 2015. Factors affecting adoption of online banking: A meta-analytic structural equation modeling study. Information \& Management, 52(2), pp. 210-226

[24] Petter, S. and McLean, E.R., 2009. A meta-analytic assessment of the DeLone and McLean IS success model: An examination of IS success at the individual level. Information \& Management, 46(3), pp. 159-166.

[25] Rogers, E. M., "Diffusion of Innovations (3rd edition)”, The Free Press, 1983.

[26] Rousseeuw, P. J., "Silhouettes: A Graphical Aid to the Interpretation and Validation of Cluster Analysis," Journal of Computational and Applied Mathematics, 1987, (20), pp. 53-65.

[27] Schacht, S., Morana, S., Urbach, N., and Maedche, A., "Are You a Maverick? Towards a Segmentation of Collaboration Technology Users," Thirty-Sixth International Conference on Information Systems-Fort Worth, 2015.

[28] Schaninger, C.M., Lessig, V.P. and Panton, D.B., 1980. The complementary use of multivariate procedures to investigate nonlinear and interactive relationships between personality and product usage. Journal of Marketing Research, pp. 119-124.
[29] Seddon, P.B., 1997. A respecification and extension of the DeLone and McLean model of IS success. Information systems research, 8(3), pp. 240253.

[30] Song, H. S., Kyeong Kim, J., and Kim, S. H., “Mining the Change of Customer Behavior in an Internet Shopping Mall,” Expert Systems with Applications, 2001, 21, (3), pp. 157-168.

[31] Stafford, T. F. 2003. "Differentiating between adopter categories in the uses and gratifications for internet services,” IEEE Transactions on Engineering Management, 50, (4), pp. 427-435.

[32] Straub, M., Limayem, M. and Karahanna-Evaristo, E., "Measuring System Usage: Implications for IS Theory Testing," Management Science, 1995, 41, (8), pp. 1328-1342.

[33] Venkatesh, V., Brown, S. A., Maruping, L. M., and Bala, H., "Predicting Different Conceptualizations of System Use: The Competing Roles of Behavioral Intention, Facilitating Conditions, and Behavioral Expectation,” MIS Quarterly, 2008, 32, (3), pp. 483502.

[34] Walldén, S., Mäkinen, E., and Raisamo, R., “A Review on Objective Measurement of Usage in Technology Acceptance Studies," Universal Access in the Information Society, 2015, pp. 1-14.

[35] Wind, Y., "Issues and Advances in Segmentation Research,” Journal of Marketing Research, 1978, pp. 317-337.

[36] Wu, T., Lu, Y., Gong, X., and Zhang, M., "Does Adoption Mean the Same to Every User? A Study of Active and Passive Usage of Mobile Instant Messaging Applications," Thirty-Sixth International Conference on Information Systems-Fort Worth, 2015.

[37] Xu, J. D., Benbasat, I., and Cenfetelli, R. T., "Integrating Service Quality with System and Information Quality: An Empirical Test in the EService Context,” MIS Quarterly, 2013, 37, (3), pp. 777-794.

[38] Yu, C. "Factors Affecting Individuals to Adopt Mobile Banking: Empirical Evidence from the UTAUT Model,” Journal of Electronic Commerce Research, 2012, 13 (2), pp. 104-121.

[39] Zhou, T., “An Empirical Examination of Continuance Intention of Mobile Payment Services," Decision Support Systems, 2013, 54, (2), pp. 1085-1091 